Janja Vollmaier Lubej

\title{
Spomin in identiteta v romanu Očeta Vincenca smrt Petra Božiča
}

Ključne besede: Peter Božič, Očeta Vincenca smrt, individualni spomin, kolektivni spomin, travma, identiteta

DOI: $10.4312 /$ ars.12.2.151-162

Da, bolj kot živi so zahtevni mrtvi.

Ne govorijo, a jih živi slišimo.

Njihov molk nam glasno zveni v krvi.

(Boris A. Novak, Vrata nepovrata, 1.knjiga: Zemljevidi domotožja, Prvi spev: Postava)

\section{Uvod}

Peter Božič (1932-2009), pisatelj in dramatik, velja za enega osrednjih modernih slovenskih pisateljev, za začetnika modernizma, ki prične literarna besedila objavljati $\mathrm{v}$ petdesetih letih 20 . stoletja, ko je v literaturi prevladoval socialni realizem, a so se nekatera literarna dela, med njimi tudi njegova, močno oddaljevala od te literarne usmeritve. Božičev odklon od socialnega realizma se razkriva skozi pomenski in oblikovni vidik njegovega pisanja (prim. Vidali, 2002, 227), pri čemer se je stvarnost v njegovi literaturi pojavljala »le še fragmentarno, tako da drobce le-te naplavlja znan, vendar do takrat v slovenski literaturi še ne udomačen modernistični jaz« (prav tam). S prvim romanom Izven (1961) se Božičev literarni svet kaže kot eksistencialistični, literarno besedilo pa je »zgled poetike svojega časa, pravi manifest (slovenskim razmeram prirejenega) eksistencializma « (Vidali, 2002, 234). Med romanoma Na robu zemlje (1968) in Zemlja (1976) je Božič napisal roman Jaz sem ubil Anito (1972), za katerega je prejel nagrado Prešernovega sklada in ki še ohranja tip eksistencialističnega romana, in nadrealistični roman Na njeni travi (1976), ki podobno kot kasnejši vojni, spominski roman Očeta Vincenca smrt (1979) velja za kolektivni roman, a po ugotovitvah Petre Vidali kljub temu nima drugačnih spoznanj kot poprejšnja romana, tako posameznik kot skupnost sta namreč »izven « $(2002,245)$, sta obstranca, odvečneža ipd. Sledi roman Chubby was here (1987); naslovna oseba ima poteze pesnika Vojina Kovača Chubbyja, ki je bil »del umetniško-intelektualne druščine, ki se je sestajala v 
slovitem lokalu Šumi« (Klun, 2009), kamor je Peter Božič rad zahajal. Zadnji Božičev roman je Zdaj, ko je nova oblast (1993). Peter Božič je tudi avtor številnih dram in velja za predstavnika drame absurda. Na Božičevo pisanje literature, ki je bila zanj duševna, osebna terapija (Möderndorfer, 1999), je vplivala njegova vojna izkušnja, kajti leta 1945 je »doživel človeka in življenje kot absurd « (Zadravec, 2001, 24). »Doživljal ga je kot zlo, kot demona, kot evropsko grozo. Če bi to grozo opisal realistično, se duševno ne bi ozdravil. Izpovedati je moral pretres/šok, svoj strašni/prestrašeni Jaz« (Zadravec, 2001, 24).

\section{Očeta Vincenca smrt}

Roman Očeta Vincenca smrt je torej Božičev četrti roman. Poleg Božiča so smrt in vojno v povojnih slovenskih romanih obravnavali še drugi, prav tako osrednji moderni slovenski avtorji, na primer Vladimir Kavčič, Lojze Kovačič, Pavle Zidar in Vitomil Zupan. Božičev roman literarni zgodovinarji (Kermauner, 1979, 250; Borovnik, 2001, 173; Zadravec, 1997, 181, idr.) označijo za kolektivni roman, saj predstavlja usodo vaščanov, vasi »in vsako posamezno zgodbo še podaljša v današnje dni, do popolnih osamljenosti in smrti« (Kermauner, 1979, 250). Tako v Očeta Vincenca smrt nobena izmed literarnih oseb ni v ospredju, vse so enakovredne. Ob tem pa sta tako družina kot primarno zatočišče posameznika kot tudi vaška skupnost razklani, razjedeni in nefunkcionalni. Vaščani ne delujejo kot skupina, niso povezani in med njimi ni nikakršne harmonije, še več, med njimi vladata sovraštvo in izdaja. Tako na primer literarna oseba Johana Zakšek, ki je bila v Rajhenbergu (kjer je med drugim spoznala Ljubo Prenner), ki ji vojna prav tako ni prizanašala, v pismu Miri leta 1965 potoži, da jo je vaška skupnost izločila, ker da je vsa njena družina izdajalska, njen mož je izdajalec in tudi sama je izdajalka. Ker ni imela njive in ni mogla oddati pšenice, je morala kopati po svojem vrtu, saj je sovaščan Župančič trdil, da jo je skupaj z možem skrila v zemljo.

In sem kopala, dve ure, in kaj sem takrat mislna, to se še dons spomnim. Da so vsi na oblast glih, da je tale Bohte in ta mal Župančič še bl žleht kot je bil lagerfirer brez roke in da sta tko žleht, da me bosta ustrelila, da kopljem grob tm na vrt in pokopala tm. Govorl so tud ldje, da so že enga kmeta takrat tudi ustrelili, k ni mel šenice, k je ni sjal kot jez (Božič, 2004, 80).

Ko sta jo vklenila in peljala po vasi, so vsi gledali: ljudje, ki jim je Zakšek pomagal, jim nosil kruh, a sedaj ga vidijo le še kot izdajalca, prav takšna pa je v njihovih očeh tudi njegova žena.

In to sem mislna takrat ko sem si kopala grob, pa ni bil grob, ampak hudobija ta mejhnga Župančiča, in takrat sem rekla, da zares ni Boga, ko so pa ldje tak, 
da pozabjo vse dobr in si zapomnijo en usran podpis, in tist podpis je vse, ne pa tist, kr je Zakšek delou, kako dobr je bil (Božič, 2004, 81).

Pismo je tudi izraz jezikovne razplastenosti v Božičevi prozi, preplet knjižnega jezika z neknjižnim, z germanizmi in narečjem. In ker ta jezik opisuje surovost in krutost, je mestoma tudi grozljiv, grotesken, "neintimističen«, dejstven. Božičeve osebe so ljudje izven, nepomembneži, obrobneži, ki ne uporabljajo lepe, knjižne slovenščine (Zadravec, 1997, 185-186). Tako kot na motivno-tematski ravni se razklanost, depersonalizacija, obup, groza in zlo kažejo tudi na jezikovno-slogovni ravni. Božičev jezik »dosega kar najhujšo neposrednost primarnega barbarskega ubijanja, hlepenja, bežanja (Kermauner, 1979, 256). Podobno jezikovno stvarnost, asociativnost, nedorečenost in pretrganost lahko beremo tudi na nekaterih mestih $\mathrm{v}$ Kosmačevem romanu Pomladni dan (1953), ki prav tako tematizira vojno.

S tem ko se razklanost kaže tako na motivno-tematski kot tudi na jezikovnoslogovni ravni, je nakazano, da je v Božičevem neusmiljenem, surovem, izpraznjenem in izvotljenem literarnem svetu porušeno vse, kar se porušiti da: torej intimna skupnost in širši kolektiv. Družba v romanu je razkrojena. V tem svetu razpade vrednostni sistem, dovoljeno je ubijanje in pretepanje, fizično nasilje.

$\mathrm{V}$ romanu ni svojosti, ni jaza, ki bi izstopal in določeval posameznika: kot piše Taras Kermauner, so vsi »isti« lik, vse je »podoba stradeža, pohlepa, boja za obstanek, sovraštva, izdajstva, besa, muke, umiranja in smrti« (Kermauner, 1979, 250). Med vaščane je namreč posegla vojna in vse zaznamovala $z$ enako vojno travmo. Roman, pripovedovan z otroške perspektive dečka Ana, ne teče kronološko, linearno, temveč je njegova zgradba mnogo bolj zapletena in kompleksna, vsebuje namreč miselne, časovno-prostorske preskoke, asociacijsko vključuje množico oseb itd. Zaradi te odlike, »disociacijsko-asociacijske zgradbe« (Zadravec, 1997, 181), je roman "mozaična podoba in odvod evropskega kaosa, ki so ga povzročili načrtovalci in izvajalci 'tisočletnega' nacističnega reda (prav tam). Zaradi tematike, zaradi z otroške perspektive podane zgodbe o neusmiljeni preteklosti ter krutosti in surovosti druge svetovne vojne, zaradi resnice, ki ni izmišljena, Kermauner ta roman označi tudi za »kroniko sveta - umora« $(1979,251)$.

Dogajalni čas romana je obdobje od leta 1941 do konca vojne in nekaj let po njej. An je deček, ki živi z očetom Joškom, mačeho Marijo (ta je Vincencova hči) in sestro Tejo. Večkrat je tepen - nasploh je telesno kaznovanje v romanu precej pogosto. Spominja se svojega otroštva v Mariboru in na Dolenjskem. Vincenc, ki se z imenom pojavi v naslovu romana, je bil prekajevalec, mesar in veleposestnik, do Ana in nasploh do otrok je bil prijazen, Ana ni pretepal in vedno mu je kaj dal, odrasli pa so ga videli drugače. V romanu sta izpostavljena boj za obstanek na eni in popolna razčlovečenost 
na drugi strani. An je deček z vojno izkušnjo in kot otrok vso tragiko dogajanja podaja neposredno, brez prikrojevanja in olepševanja. An in Teja na jasi vidita številna trupla - s smrtjo se srečujeta tako rekoč vsakodnevno. An vojnih travm ne more preseči in predelati, zato konča kot klatež in alkoholik.

$\mathrm{V}$ romanu je zaradi neizogibnega trpljenja poudarjena surovost. In ta surovost se stopnjuje v razčlovečenje, v izgubo dostojanstva, v nesvobodno izbiro, ki posameznika sili bodisi v krajo bodisi v prostitucijo. Če za najintimnejšo skupnost, družino, v tem romanu velja, da v njej razpadejo vse vrednote, je takšna tudi širša družba, širši literarni svet Petra Božiča, kajti v tem razklanem, razosebljenem svetu je dovoljeno tudi ubijanje, še več, po Kermaunerjevi oceni je celo zahtevano (1979, 259). Pri tem pa ni zanemarljiva otroška perspektiva dečka, skozi katero je predstavljeno dogajanje: več literarnih zgodovinarjev je namreč poudarjalo pomen takšnega pripovedovanja (Borovnik, 2001; Zadravec, 1997, 185), saj naj bi vzbujalo vtis, da je neizmišljeno, nepokvarjeno, otroško iskreno, prvinsko (prim. Borovnik, 2001, 173-174). Otroška pripovedna perspektiva vidi dogajanje brez ideoloških, moralnih in kultivirano-kulturnih predsodkov, idej, vrednot in meril (Kermauner, 1975, 127). Po Kermaunerjevem mnenju (132-133) naj bi jo v slovensko književnost prvi uvedel Lojze Kovačič.

An tako februarja 1945 opazuje tridnevno bombardiranje Dresdna. Ti opisi so realistični in brez podajanja občutij, $\mathrm{v}$ resnici tako prepričljivi, da si za njimi zlahka zamišljamo otroka, dečka, ki jih gleda.

Čez tri dni, ko je spotoma srečal kupe napihnjene crknjene živine in tudi do kraja zoglenelih trupel, ki so še malo gorela, saj ves fosfor od fosfornih bomb ni zgorel niti tedaj, ko je prežgal kosti, je šel v Dresden, da bi videl, kako je, če zbijejo kako mesto do tal (Božič, 2004, 86).

Tudi Peter Božič je sam neposredno doživljal podobne prizore vojnega nasilja (opazoval koncentracijsko taborišče v Vroclavu, gledal tridnevno bombardiranje Dresdna). Deček An, njegov pripovedni lik, te travmatične vojne izkušnje ni zmožen (sposoben) preseči. Ob odsotnosti odrasle avtoritete teh grozot in surovosti ne predela, zato se zapije in izgine, konča torej na dnu. Tako njegov bivanjski problem ostaja nerešljiv. Bivanjska stiska, kot opaža Miran Štuhec (1995, 59), se pojavlja že v predhodnih Božičevih pripovednih besedilih. Po njegovem prepričanju je Božičevo pripovedništvo do leta 1972 proza, »ki nosi v svojem bistvu problem človekove osamljenosti, (samo)izločenosti, sprtosti z okoljem, razočaranje, prepričanje, da je posameznikovo dejanje že vnaprej obsojeno na propad, $[\ldots] \lll(1995,60)$. 


\section{Spomin}

Vojni roman Očeta Vincenca smrt temelji na avtorjevih osebnih izkustvih, ki jih je doživljal kot deček, zato to literarno delo vsebuje avtobiografske prvine. Toda, kot piše Alenka Koron, spominjanje je podvrženo samoprevari in zlahka preide $\mathrm{v}$ "proces, v katerem postane rekonstrukcija konkretnega doživetja, tako indikativnega za avtobiografijo, če že ne nezmožna, pa vsaj resničnostno nepreverljiva« $(2008,11)$. Enako o spominjanju piše Peter Burke, ki v skladu s svojo teorijo in dognanji psihologa Fredericka Barletta trdi, da »dogodke v času nezavedno obdelamo znotraj splošnih shem, ki so lastne vsaki kulturi. Te sheme dovoljujejo spominom, da se lahko ohranijo, vendar v izkrivljeni obliki« (Burke, 2007, 76, povz. po: Širok, 2012, 138). Teorije o prevladi individualnega spomina nad kolektivnim (Ricoeur, Olick) trdijo, da je »spominjanje individualni pojav, saj posameznik sam izraža bojazni, strahove, emocije iz svoje preteklosti«. Spomin je tako »subjektivna izkušnja, ki pomaga pri oblikovanju posameznikove identitete (Širok, 2012, 139). Po drugi strani pa francoski sociolog Maurice Halbwachs trdi, da spomine oblikujejo kolektivne entitete. Spominjanje zanj ni »individualno dejanje, temveč poteka ob pomoči spominjanja drugih članov skupnosti«. Spomini ne pripadajo posamezniku (Širok, 2012, 140). Vendar pa ima spominjanje tako individualne kot kolektivne dejavnike; obe vrsti spomina sta $\mathrm{v}$ tesnem medsebojnem odnosu. Kolektivni in individualni spomin vzajemno vplivata drug na drugega in se sooblikujeta (Širok, 2012, 140). V teorije spominjanja se vključuje tudi Freudova psihoanaliza, ki spomine opisuje kot proizvod nezavednega, cilj pa je prekriti resnične travmatične izkušnje in jih prirediti v znosnejše (Jurić Pahor, 2007, 208). Tako je tudi literarno pisanje, ki se nanaša na izkušnje vojne, v primeru Petra Božiča mogoče razlagati kot pobeg iz boleče, $z$ vojnimi strahotami in surovostmi naphane preteklosti. Na tem mestu naj izpostavim esej Jaroslava Skrušnýja v knjigi Varuhi spomina. Literarna pisava kot poslednje profano obredje dvajsetega stoletja (2009), v katerem piše o pomenu literarne pisave; ta »kliče v spomin nezaceljivo rano, ki razpolavlja srce novoveškega človeka od trenutka, ko se je znašel v razliki med svojo smrtno narojenostjo na eni in zgodovinsko poklicanostjo za preureditev sveta (po nareku višjega smisla, ideje) na drugi strani (Šeligo)« (2009). Skrušný dodaja, da literatura tematizira »krik skrajne groze in obupa tistega posameznika, ki so ga vsakršne odrešenjske utopije in hiliastična gibanja dvajsetega stoletja neusmiljeno potegnili $\mathrm{v}$ brezumni vrtinec in 'slepi nemir zgodovine' (E. Kocbek)« (prav tam). In ta krik groze je osrednji motiv v romanu Očeta Vincenca smrt, ki je, kot že omenjeno, navdahnjen z Božičevo lastno vojno izkušnjo. Tovrstnih besedil je v slovenski književnosti precej (in še nastajajo), med njimi je tudi veliki epos Borisa A. Novaka Vrata nepovrata, izdan v treh knjigah (Zemljevidi domotožja, 2014, Čas očetov, 2015, Bivališča duš, 2017), iz katerega je izposojen uvodni citat. Izjemna pesnitev tematizira individualni, intimni in 
kolektivni slovenski spomin ter se pri tem opira na zgodovinske prelomnice, na primer na obe svetovni vojni in povojne poboje, ter jih umešča $\mathrm{v}$ kontekst individualnih izkustev, intimnih doživetij svojih prednikov in drugih. O pomenu preteklosti, preteklih dogodkov, spoznanj, doživetij za sedanjost in svojost, o neizogibnosti lastne individualne/kolektivne preteklosti piše Novak takole:

Še zmeraj je tam, / še zmeraj sta tam, / še zmeraj so vsi tam, / in bodo na vekomaj, / še zdaj zveni ta pesem, / slišim jo, / kot bi na morsko dno potonil rojstni raj, / ljube obraze vidim čisto jasno, / tam na dnu, / odtisnjene v noč. (Boris A. Novak, Vrata nepovrata, 2. knjiga: Čas očetov, Petdeseti spev: Čas slovesa)

Če Božič v svoji pripovedi posredno prikazuje delovanje spomina v svojih literarnih likih, Boris A. Novak torej neposredno tematizira tudi samo spominjanje in spomin, pri čemer se srečuje $\mathrm{z}$ intimnim in kolektivnim spominom. Pri njem so tematizirana tako zgodovinska »dejanja « kot tudi »intimna junaštva, ki jih zgodovinopisje praviloma spregleduje« (Vrečko, 2017, 1070). Vrečko ugotavlja, da zato, ker "pesnik izenačuje Jaz in svet«, Novak uvaja "posebno metodologijo dela: ep je pesem spomina, prisluškovati je treba prednikom in lastnim sanjam o njih « $(2017,1091)$. Če je za Novaka ep pesem spomina, je za Božiča roman grozna, srhljiva pripoved, ki nastaja iz spomina. Vse, kar Božič pripoveduje, oblikuje spomin. Anov, Vincencov, Joškov, spomin vseh. Iz spominskih vsebin raste vse večja odtujenost pripovednih likov. Anov individualni spomin je ponazorjen v spominjanju na primarno družino, kjer s sestro Tejo nista deležna topline doma, družine $\mathrm{v}$ tem romanu ni, o družini sploh ni mogoče govoriti, družina je v Božičevem tekstu že v osnovi razbita, razprta (Kermauner, 1975, 154). Anov in Tejin oče Jošk je odsoten, po ženini zgodnji smrti se vnovič poroči in skupaj z novo ženo trpinči otroka. An in Teja živita v patološki, nefunkcionalni družini, kjer nista deležna sprejemanja, razumevanja in ljubezni. Tako je ena od pomembnih tem romana tudi odsotnost očeta in matere. ${ }^{1}$ Bolj kot mačeha, ki trpinči Ana in Tejo, je problematičen oče, ki je prav tako fizično nasilen, saj svojih otrok ne vzgaja in jima ne nudi varnega zatočišča. Izhajajoč iz psihodinamične teorije, katere utemeljitelj je Sigmund Freud, je človek psihološko bitje, ki razumeva, ustvarja, čuti in deluje $\mathrm{z}$ drugimi. Za to teorijo so pomembne pretekle izkušnje, $z$ vidika katerih noben simptom ali vedenje ni naključno. Vse obnašanje je določeno s preteklimi izkušnjami, zlasti v otroštvu (Comer, 1995, 36). Psihodinamični vidik upošteva tudi teorija objektnih odnosov (pojem povzet po: Žvelc, 2011, 27); pomembni so izključno človeški objekti, ker "potreba po vzpostavitvi odnosov z drugimi primarno motivira posameznika«

1 Ta v slovenski književnosti ni novost, temveč se pojavlja že pred Božičem, tako na primer pri Cankarju »ni očeta, avtoritativnega moškega« (Jensterle Doležal, 2002, 111). Podobna tematizacija se kaže pri Cirilu Kosmaču v noveli Pot v Tolmin (Borovnik, 2012, 151). Danes pa se s podobno temo ukvarjajo tudi avtorji in avtorice mlajše generacije, na primer Goran Vojnović, Gabriela Babnik idr. 
(Comer, 1995, 43). Neprimerna in pomanjkljiva vzgoja ter slabi odnosi vodijo v fiksacijo, nenormalni razvoj in psihične težave (prav tam). An in Teja nista deležna starševske ljubezni in sprejemanja, »frustracija potrebe po ljubezni in sprejemanju ljubezni (pa je) največja travma, ki jo otrok lahko doživi« (Žvelc, 2011, 31). Tako v vojnem času, ki že sam po sebi povzroča travmatične izkušnje, doživljata še osebno stisko. Porušeni odnosi v družini so tako v romanu stalnica, Anov zaupnik je le oče Vincenc. An si ne more oblikovati identitete, ker ga zaznamujejo konfliktno otroštvo, nerazrešene smrti v vojnem času, beg in iskanja v povojnem obdobju, preostane mu le pijančevanje in klateštvo. Opore nima niti v družini niti v širši vaški skupnosti, na kateri bi se lahko oprl. Anov spomin se osredinja tudi na preplet individualnega in kolektivnega, ko intimno, tj. njegova družina, preraste v kolektivno, v izkušnjo vojne, pri čemer so poudarjeni človeška krutost, popolna odsotnost empatije, absolutno razvrednotenje posameznika ter degradacija človeškega in širše skupnosti tako na ravni krivcev kot žrtev.

Toda spričo vključitve WHW v ekonomijo naroda je bil čisti dobiček na primer 10 dekagramov las, ki so jih porabili za vse vrste tesnil namesto dragega in uvoženega kavčuka, [...], potem kosti za umetna gnojila, ki jih je bilo v prahu zmeraj približno za kilogram ali pa malo manj (Božič, 2004, 270).

Ko sta jedla, ga je štandarenfirer spraševal, kako da je ostal živ, saj je bil tam v središču, kjer je železniška postaja, največji pekel in so tam ljudje kar skakali $\mathrm{v}$ vodo in so morali on in njegova desetina streljati v tiste ljudi, ki so bili ožgani od fosforja in so jim tako olajšali smrtne muke. Reka pa je s seboj odnesla vse te muke našega naroda, je rekel SS štandarenfirer in če niso pravi ljudje zraven, lahko take muke samo pomehkužijo in spravijo še tako trdno ljudstvo v obup (Božič, 2004, 196-197).

Čez dve uri je mrak in malo delj časa nepretrgane vožnje. Vsi so pozabili na smrt tistih dveh. Nihče se $v$ tem transportu ne spominja smrti delj kot pol ure. Potem pridejo na vrsto vsakdanji opravki, potem pride tesnoba med pločevinasto streho vagona in med sedeži in med prtljažniki (Božič, 2004, 176).

\section{Identiteta}

An in vse druge literarne osebe so soočene s travmo. Travmo praviloma povzročajo »dogodki, ki so zunaj normalnega človeškega izkustvenega in predstavnega sveta. Zato uničijo in preplavijo njegov varovalni sistem, s katerim sicer razume in obvladuje situacije« (Jurić Pahor, 2001). Travmatična izkušnja razceplja posameznika. Kar je pretrgano, ni mogoče zlahka popraviti, zlepiti. Zdi se, kot da imamo pred seboj dve 
identiteti (prav tam). Pred našimi očmi se razgalja An in ostale, prav tako pomembne literarne osebe, a če se ozremo samo nanj, vidimo, da imamo pred seboj dečka Ana, otroka, in Ana, ki je že odrasel, a zaradi nepojmljivo grozljivega časa blodi in išče svoje mesto v svetu. Identiteta se oblikuje vse življenje, a videti je, da so osebe v romanu obtičale $\mathrm{v}$ času in prostoru, tam ni nobenih pomikanj, nobenih sprememb, poudarkov, vse je isto in nič se ne spremeni. Identiteta po Nastran Ule "pomeni kontinuirano, vztrajno istost med dvema entitetama ali dvema stanjema entitete, npr. dvema trenutkoma $\mathrm{v}$ času. Identiteta je izhod, zaključek percepcije in kognicije prostora, časa in sebe $\mathrm{v}$ njem. Identiteta se nanaša na notranje asociacije in primerjave, $\mathrm{v}$ katerih določene esencialne kvalitete ostanejo nespremenjene kljub spremembi v stanju, času ali spremembi drugih esencialnih kvalitet « (Nastran Ule, 2000, 85-86). Anu umanjka ravno to, kognicija prostora, časa in sebe $\mathrm{v}$ njem. Z vračanji v travmatično preteklost, $\mathrm{s}$ časovnimi preskoki je njegov svet $\mathrm{v}$ sedanjosti, zdajšnjosti omejen, $\mathrm{z}$ otroškimi očmi zroč v prihodnost, ki je ni, oziroma prihodnost, ki bo težka:

Pa ne zaradi tega, ker je bilo leto 1941; zanj se je pričenjala druga vojna, mnogo prej in mnogo pozneje, prav na tistem mestu, kjer je bila samo še sled groba očeta Vincenca med samomorilci, ubijalci, obešenci, potepuhi in samimi izgubljenimi ljudmi (Božič, 2004, 286).

V Božičevem literarnem svetu je nenehno prisoten spomin na grozo. Obup in navzočnost preteklega sta prehuda za oblikovanje zdajšnjosti. Prav tako se Anova identiteta ne more izoblikovati v lastno singularnost, on namreč blodi, se išče, izgublja, beži, pri njem kot žrtvi umanjka dodeljenost »mesta družbenega samouvrščanja posameznika« (Nastran Ule, 2000, 192) in tudi to, da bi »identitete govorile skozi nas, skozi naš diskurz, skozi naše delovanje, naše vodenje življenja« (prav tam). Niti identitete drugih se $\mathrm{v}$ tako nagnitem času in prostoru ne morejo izoblikovati, vsi ljudje so enaki, isti, določujejo jih krute izkušnje, ki »ne morejo stesati prihodnosti« (Kermauner, 1979, 251), opredeljuje jih trpljenje, ki »ne more odkupiti odrešitve« (prav tam). V romanu, poudarja Kermauner, je subjektiviteta podrejena objektiviteti (prav tam). Za reizem, s katerim Kermauner povezuje Rudija Šeliga, Lojzeta Kovačiča in Petra Božiča, velja, da »človek sploh nima identitete s samim sabo, ki bi ga varovala pred zamenjavo z drugimi posamezniki ali z rečmi. Identiteta je temeljni znak vsega: vse je zamenljivo z vsem« (Kermauner, 1979, 159-160).

In tudi zato, ker ni identitete, ni prihodnosti, temveč životarjenje. In tako je skozi tragično literarno zgodbo podana dvojnost katastrofe, ki jo povzroči vsakršna vojna: žrtvam in svojcem žrtev se individualni, intimni spomin in kolektivni spomin $\mathrm{z}$ najhujšo ostrino zarežeta $\mathrm{v}$ največjo globino. Zato je ta svet $\mathrm{v}$ Božičevem romanu brezupen, brezdanji. 


\section{Zaključek}

Očeta Vincenca smrt je modernistični roman enega osrednjih povojnih slovenskih pisateljev, Petra Božiča, ki še z nekaterimi, na primer z Lojzetom Kovačičem, Jožetom Snojem, Marjanom Rožancem idr., skozi otroške oči oziroma otroško perspektivo podaja grozo naše skupne preteklosti, strahoto in surovost vojne. Deček An te travme ne more predelati in je preseči, izgublja se v labirintu blodenj in iskanj. Božičev literarni svet je v romanu dokončno nagnit, razosebljen in razvrednoten; je svet, v katerem zaradi tragičnih spominjanj, tako individualnih kot kolektivnih, ni mogoče vzpostaviti nove, boljše skupnosti in prihodnosti. So le isti liki brez trdne identitete, brez svojosti in subjektivizacije. Pisatelji starejše generacije, med katere uvrščamo Petra Božiča, so lahko vojno izkušnjo popisali neposredno, najnovejša literarna zgodovina pa beleži literarna dela avtorjev, ki neposredne izkušnje druge svetovne vojne niso imeli, zato je njihova pripoved ali upesnitev v primerjavi z Božičevo drugačna tako na motivnotematski kot tudi jezikovno-stilni ravni (tak je na primer v prispevku že omenjeni in $\mathrm{z}$ Veronikino nagrado nagrajeni epos Vrata nepovrata Borisa A. Novaka ali s kresnikom nagrajeni Vojnovićev roman Jugoslavija, moja dežela). Napisano dokazuje, da vojna kot tema iz intimnega, individualnega spomina prerašča, se spaja in oplaja v kolektivni/em spomin/-u (ali narobe) in identiteto.

\section{Bibliografija}

Borovnik, S., Razvoj pripovedne proze po letu 1945, v: Slovenska književnost III (ur. Pogačnik, J. in dr.), Ljubljana 2001, str. 145-202.

Božič, P., Očeta Vincenca smrt, Ljubljana 2004.

Božič, P., Izven. Jaz sem ubil Anito, Ljubljana 2002.

Jurić Pahor, M., Narativnost spominjanja: vpogledi v avto/biografsko usmerjeno raziskovanje in v govorico ekstremne travme, v: Avtobiografski diskurz (ur. Koron, A., Leben, A.), Ljubljana 2001, str. 161-173.

Klun, A., Peter Božič, kronist življenja ljudi z roba družbe, 2009, https://www.rtvslo. si/kultura/knjige/peter-bozic-kronist-zivljenja-ljudi-z-roba-druzbe/207255 [1. 9. 2018].

Kermauner, T., Živeti pekel, v: Božič, P., Očeta Vincenca smrt, Ljubljana 1979, str. 249259.

Kermauner, T., Zgodba o živi zdajšnosti, Maribor 1975.

Möderndorfer, V., Človek v šipi - portret Petra Božiča (kratki dokumentarni TV film), TV Slovenija, Ljubljana 1999. 
Novak, B. A., Vrata nepovrata, 1. knjiga: Zemljevidi domotožja, Novo mesto 2014.

Novak, B. A., Vrata nepovrata, 2. knjiga: Čas očetov, Novo mesto 2015.

Novak, B. A., Vrata nepovrata, 3. knjiga: Bivališča duš, Novo mesto 2017.

Nastran Ule, M., Sodobne identitete - V vrtincu diskurzov, Ljubljana 2000, str. 85-86.

Skrušný, J., Varuhi spomina. Literarna pisava kot poslednje profano obredje dvajsetega stoletja, Maribor 2009.

Širok, K., Kolektivni spomin, pričevalec in zgodovina: diskurzivne konstrukcije preteklosti, Acta Histriae 1-2/2012, str. 137-150.

Vidali, P., Prozni opus Petra Božiča - dosleden v svojem niču, v: Božič, P., Izven. Jaz sem ubil Anito, Ljubljana 2002, str. 227-255.

Vollmaier Lubej, J., Patološki odnos med materjo in hčerjo/sinom v prozi Gabriele Babnik in Gorana Vojnovića, Jezik in slovstvo 59/4, 2014, str. 79-95.

Vrečko, J., Poezija kot zgodovina in obujeni ep, v: Novak, B. A., Vrata nepovrata, 3. knjiga: Bivališča duš, Novo mesto 2017, str. 1070-1102.

Zadravec, F., Slovenski roman 20. stoletja, Murska Sobota, Ljubljana 1997. 
Janja Vollmaier Lubej

\section{Spomin in identiteta v romanu Očeta Vincenca smrt Petra Božiča}

Ključne besede: Peter Božič, Očeta Vincenca smrt, individualni spomin, kolektivni spomin, travma, identiteta

Prispevek se ukvarja $\mathrm{z}$ romanom sodobnega slovenskega pisatelja in dramatika Petra Božiča (1932-2009). V središče postavlja travmatično vojno izkušnjo, izkušnjo smrti in vprašanje oblikovanja identitete ob veliki travmi literarnih oseb, pri čemer ima spomin v pripovednem svetu Petra Božiča temeljni pomen. Predstavljena so pisateljeva pripovedna besedila, čemur sledi poglobljena interpretacija romana Očeta Vincenca smrt s temeljnimi motivno-tematskimi, stilnimi in jezikovnimi poudarki. Zatem se avtorica posveti podrobnejši predstavitvi spomina dečka Ana ter identitete literarnih oseb. Ugotavlja, da v romanu prevladujeta preplet individualnega in kolektivnega spomina ter odsotnost identitete zaradi travm iz preteklosti. 
Janja Vollmaier Lubej

\section{Memory and Identity in Peter Božič's Novel The Death of Father Vincent}

Keywords: Peter Božič, The Death of Father Vincent, individual memory, collective memory, trauma, identity

The article deals with a novel by the contemporary Slovenian writer Peter Božič (1932-2009). It presents traumatic war experiences, death experiences and the question of identity formation, and the issue of memory plays a key role in this. The articles discusses the literary texts of Peter Božič and an interpretation of the novel The Death of Father Vincent, with an emphasis on its stylistic, linguistic, and thematic aspects. The article also presents the memory of a boy An, his identity and the identities of other characters. It is established that the novel shows the intertwining of individual and collective memory, and also the absence of identity because of past trauma. 